\title{
FÓRUM
}

Submetido 30.06.2019. Aprovado 04.05.2020

Avaliado pelo sistema double blind review. Editores convidados: Diego M. Coraiola, Amon Barros, Mairi Maclean e Willian M. Foster Versão traduzida

DOI: http://dx.doi.org/10.1590/So034-759020210105

\section{CONTROVÉRSIAS COMO MÉTODO PARA ANTI-HISTÓRIA}

\author{
Controversies as method for ANTi-history \\ Controversias como método para la Antihistoria
}

\section{CÉSAR TURETA ${ }^{1}$ \\ cesartureta.ufes@gmail.com 0000-0003-0091-1114}

\section{BRUNO AMÉRICO'}

brunolaa@hotmail.com 0000-0003-2615-6583

\section{STEWART CLEGG 2,3}

Stewart.Clegg@uts.edu.au o000-0001-6083-4283

1 Universidade Federal do Espírito Santo, Departamento de Administração, Vitória, ES, Brasil

2 University of Technology Sydney, Sydney, New South Wales, Australia

3Universidade Nova de Lisboa, NOVA School of Business and Economics, Lisboa, Portugual

\section{RESUMO}

Nosso objetivo é construir uma proposta de método para os ANTi-historiadores, tomando a análise da controvérsia como ponto de partida. Apesar do desenvolvimento teórico e metodológico da abordagem ANTi-história para o estudo do conhecimento do passado e a criação de sua história, há espaço para o desenvolvimento de um método com base na análise de controvérsias. Baseamos nossa proposta em algumas das suposições da ANTi-história (relacionalismo, princípio de simetria e multiplicidade) e conceitos práticos (tradução e política de redes de atores). Além disso, recomendamos quatro critérios que os pesquisadores devem usar na escolha de uma controvérsia para servir como ponto de partida para a investigação. Por fim, apresentamos cinco etapas para colocar em ação a investigação do conhecimento do passado e a criação da história.

PALAVRAS-CHAVE | ANTi-história, história organizacional, controvérsias, virada histórica, teoria-ator-rede.

\section{ABSTRACT}

Our aim is to develop and propose a method for ANTi-historians, using analysis of controversy as the starting point. Despite the theoretical and methodological development of the ANTi-history approach to the study of knowledge of the past and the creation of its history, there is room for method development based on controversy analysis. We ground our proposal in some of ANTi-history's assumptions (relationalism, the symmetry principle, and multiplicity) and practical concepts (translation and politics of actor-networks). In addition, we recommend four criteria that researchers should use in choosing a controversy to serve as a starting point for investigation. Finally, we present five steps for investigating knowledge of the past and the creation of history.

KEYWORDS / ANTi-history, organizational history, controversies, historic turn, actor-network theory.

\section{RESUMEN}

Nuestro objetivo es construir una propuesta de método para antihistoriadores, tomando el análisis de la controversia como el punto de partida. A pesar del desarrollo teórico y metodológico del enfoque ANTi-History para el estudio del conocimiento del pasado y la creación de su historia, hay espacio para el desarrollo de un método basado en el análisis de controversias. Basamos nuestra propuesta en algunos de los supuestos de la ANTi-History (relacionalismo, principio de simetría y multiplicidad) y conceptos prácticos (traducción y política de redes de actores). Además, recomendamos cuatro criterios que los investigadores deben usar para elegir una controversia que sirva como punto de partida para la investigación. Finalmente, presentamos cinco pasos para poner en práctica la investigación del conocimiento del pasado y la creación de la historia.

PALABRAS CLAVE / Antihistoria, historia organizacional, controversias, giro histórico, teoría del actor-red. 


\section{INTRODUÇÃO}

Apesar de a história ser uma dimensão importante da contemporaneidade das organizações (Ocasio, Mauskapf, \& Steele, 2016), seu papel foi marginalizado e esquecido na pesquisa de gestão convencional, como tem sido demonstrado recentemente por autores (Coraiola, Suddaby, \& Foster, 2017; Maclean, Harvey, \& Clegg, 2017). A virada histórica nos estudos organizacionais (Booth \& Rowlinson, 2006; Maclean, Harvey, \& Clegg, 2016; Mills, Suddaby, Foster, \& Durepos, 2016) proporcionou mais oportunidades de estudar o passado, a história e a memória de diferentes perspectivas. Uma dessas abordagens emergentes é a ANTi-história, que tem mostrado como as versões dominantes da realidade são estabelecidas nas organizações (Corrigan \& Mills, 2012). Ambas as implicações teóricas e metodológicas da ANTi-história para pesquisar o passado e criar histórias foram foco de discussões recentes (para implicações teóricas, ver Durepos \& Mills, 2018; Mills \& Durepos, 2010; para implicações metodológicas, ver Durepos, 2015; Durepos \& Mills, 2012a).

Estudos de ANTi-história mostraram que o processo de criação da história é marcado por desacordos, conflitos e vozes marginais silenciadas (ver Corrigan \& Mills, 2012; Deal, Mills, \& Mills, 2018; Durepos, Mills, \& Mills, 2008). Para traçar a rede de atores, seria interessante começar com controvérsias e identificar situações em que os atores discordam e questionam o que era dado como certo (Venturini, 2010a). Apesar de os aspectos teóricos e metodológicos da ANTi-história serem bem desenvolvidos pela literatura especializada, o potencial de análise de controvérsias como método para a ANTi-história não é suficientemente abordado. Além disso, poucos estudos abordam a sistematização da prática de pesquisa da ANTi-história, a qual indica como uma investigação pode ser operacionalizada e dar vida a vozes marginalizadas e controvérsias suprimidas. Portanto, nosso objetivo é propor um método para ANTi-historiadores usando a análise da controvérsia como um ponto de partida razoável.

O desenvolvimento de dimensões de métodos é importante para os estudiosos da ANTi-história porque a identificação e análise de controvérsias permite explorar diferentes relatos históricos criados por atores e evita conferir um status especial a atores privilegiados (Secord \& Corrigan, 2017). Mesmo quando a superfície da realidade parece coerente e não problemática, histórias não contadas podem ganhar vida quando as controvérsias são o ponto de partida do trabalho de campo. A descrição e interpretação das práticas, interesses e relações de atores heterogêneos que retratam a história como múltipla (Durepos, 2015) podem se beneficiar da cartografia da controvérsia porque esta analisa múltiplos pontos de vista (Venturini, 2010b).

Criar uma cartografia de controvérsias é uma ferramenta útil para explorar presenças e ausências contemporâneas. $\mathrm{Na}$ condução da pesquisa ANTi-histórica, é difícil acompanhar os atores cujas vozes foram silenciadas e cujas histórias não foram contadas (Kivijarvi, Mills, \& Mills, 2018). Ao focar as divergências, permitindo observar situações em que os autores não podem ignorar uns aos outros (Venturini, 2010a), os pesquisadores podem expor as redes de associações responsáveis por produzir e obstruir realidade(s) (Venturini, 2010a, 2010b).

Recentemente, Durepos, Shaffner e Taylor (2019) manifestaram-se a favor de uma análise histórica mais crítica. A resposta pode ser a análise de controvérsias, um método pelo qual realidades ocultas e pontos de vista marginalizados podem ser implantados (Venturini, 2010a). Considerando que o desenvolvimento da ANTi-história ainda está em uma fase inicial (Mills \& Durepos, 2010), aproveitaremos o espaço para "desenvolver cada uma de suas facetas constitutivas, bem como delinear implicações práticas de pesquisa para os pesquisadores que desejam utilizar a abordagem" (Durepos \& Mills, 2017, pp. 57-58). Explorando esse espaço, apresentaremos uma proposta para operacionalização que se baseia em desenvolvimentos recentes da abordagem ANTi-histórica (por exemplo, Bettin \& Mills, 2018; Durepos \& Mills, 2017).

Após apresentar as principais ideias controversas na próxima seção, apresentaremos as suposições da ANTi-história. Posteriormente, serão apresentados os conceitos práticos utilizados para a operacionalização, juntamente com a análise de controvérsias. Em seguida, apresentaremos a proposta do método, mostrando alguns critérios para a escolha de uma controvérsia e fazendo algumas recomendações para orientar os pesquisadores no desenho de suas investigações e no planejamento de sua prática de trabalho de campo. Argumentaremos que há cinco etapas de pesquisa baseadas na análise de controvérsias que serão úteis, servindo como um guia para o estudo do passado e para a criação de um mapa da história dada como certa. Por fim, apresentaremos um exemplo prático para ilustrar brevemente as cinco etapas do método proposto.

\section{ANÁLISE DE CONTROVÉRSIA}

\section{Principais ideias}

A ANTi-história problematiza a facticidade tida como certa da história como um relato contemporâneo do passado e as práticas 
e suposições subjacentes que sustentam relatos históricos convencionais (Bettin \& Mills, 2018; Durepos \& Mills, 2018; Myrick, Mills, \& Mills, 2013). A análise de controvérsias é uma maneira útil de realizar essa tarefa porque a gênese dos processos sociais que sustentam contemporaneamente e cuidadosamente sentidos forjados de normalidade é trazida à tona, incluindo tanto as correntes que se tornaram dominantes quanto aquelas que foram dominadas (Scott, Richards, \& Martin, 1990). Além disso, vozes e pontos de vista de diversos atores entram no escopo de investigação possível (Venturini, 2010a), pois as controvérsias são constituídas por pessoas e organizações tomando partido, considerando todas as questões em jogo.

As controvérsias têm sido uma questão central desde o surgimento da teoria ator-rede (Actor-network theory - ANT ou TAR) (ver Callon, 1989). Para Latour e Woolgar (1986), “os fatos são construídos de tal forma que, uma vez que a controvérsia se estabelece, eles são tidos como certos (p. 202)". A controvérsia pode ser definida como "qualquer coisa (um discurso ou ação) que desafia o status quo entre os atores" (Hussenot \& Missonier, 2010, p. 272). Assim, a controvérsia é uma situação de desacordo entre atores heterogêneos engajados na ação (Venturini, 2010a), em que traduções alternativas buscam fixar seus diversos e contraditórios interesses (Latour, 1999). As traduções podem estar envolvidas de maneira conflituosa ou dominar o campo de tal forma que parecem ser hegemônicas, com apenas pequenas rachaduras e fissuras aparentes no verniz da concordância. 0 processo de tradução torna-se evidente durante a reconfiguração da rede de atores, fazendo com que elementos heterogêneos apareçam, sejam modificados ou excluídos (Hussenot, 2014). Para os estudos de gestão e organização (Management and organization studies - MOS), as controvérsias dizem respeito a divergências sobre a forma como uma organização, projeto ou prática organizacional é ordenada, gerenciada ou planejada (Hussenot, 2014).

Embora algumas diferenças tornem a controvérsia evidente (Venturini, 2010a), ela é distinta do conflito de relacionamentos ou tarefas (Jehn, 1995), que são situações pontuais que ocorrem e são resolvidas na vida cotidiana da organização como eventos comuns. Ocasionalmente, os conflitos podem tornar-se uma controvérsia quando uma variedade de questões sucessivas é trazida à tona (Hussenot, 2008). Nesse sentido, a controvérsia é uma noção orientada para o processo, "uma forma de acompanhar os processos da organização à medida que ela evolui ao longo do tempo" (Hussenot, 2014, p. 374).

A realidade organizacional apresenta-se naturalmente como estável e coerente, a versão típica da realidade mantida e tida como certa pelos atores. Essas características são o efeito de muito trabalho tácito possibilitando uma aparência de ordem (Law, 1994) em termos de estratégia, estrutura ou organização em geral. Porém, os processos de construção de uma versão da realidade e de sua organização raramente estão isentos de controvérsias (Latour, 2005; Venturini, 2010a). Muitas controvérsias envolvem diferentes modelos de governança, cuja base são números (Michaud, 2014), objetos (Hussenot \& Missonier, 2010) e a introdução de novas tecnologias (Lanzara \& Patriotta, 2001). Elas também envolvem interpretações e representações do passado como uma questão central no presente.

Alguns estudiosos da ANTi-história abordaram controvérsias direta ou indiretamente. Secord e Corrigan (2017) mostram que a historiografia corsária da Nova Escócia foi marcada por controvérsias entre corsários e a corte do vicealmirantado. Por meio de vários relatos do passado, os autores analisam as tensões entre as diferentes versões da história e como as controvérsias ajudaram a questionar a versão dominante da realidade. Apesar de não utilizar a noção de controvérsia, Corrigan (2016) trata as controvérsias indiretamente, analisando os conflitos entre o município de Halifax e a comunidade de Africville. 0 autor trouxe à vida atores periféricos e novas versões do passado. No entanto, esses autores não usam a controvérsia como método sistemático para mapear e descrever a rede de atores que constitui as histórias.

O método da cartografia de controvérsias pode ajudar os estudiosos da ANTi-história a investigarem redes de atores e mapear sua constituição (Durepos \& Mills, 2017) a fim de trazer a política para o primeiro plano da organização e questionar fatos tidos como certos. Os "fatos" são vistos como produtos da prática das traduções, os quais podem ser mapeados por meio da análise das controvérsias para evidenciar redes heterogêneas de atores que constituem o passado (Durepos \& Mills, 2012b). Sempre que uma situação se torna questionável, uma controvérsia é retratada em torno de vários pontos de vista. Interpretações divergentes da controvérsia devem ser descritas até que a disputa se estabilize temporariamente (Lanzara \& Patriotta, 2001). A controvérsia pode terminar com um compromisso (Venturini, 2010a) que legitime seu resultado, sendo, então, compartilhada pelos membros da organização como forma de realizar uma determinada atividade (Lanzara \& Patriotta, 2001), levando a novas relações entre os atores (Hussenot \& Missonier, 2010).

De acordo com os preceitos da ANTi-história, podemos argumentar que a solução de controvérsias colabora para a criação de uma versão dominante do passado (Corrigan \& Mills, 2012; Durepos, Mills, \& Mills, 2008). A seguir, abordaremos como isso acontece. 


\section{Suposições analíticas da ANTi-história}

\section{Relacionalismo}

O relacionalismo envolve enfatizar as relações dos atores e traçar associações que produzem conhecimento do passado (Kivijarvi et al., 2018), formando redes em vez de presumir que elas são preestabelecidas (Durepos \& Mills, 2018). Os atores que compõem as redes podem se associar ou se desassociar quando surgem controvérsias (Callon, 1989), com suas crenças, identidade e características variando enquanto o fazem (Callon, 1986). As redes de atores são heterogêneas: podem ser organizações, movimentos sociais, grupos ou indivíduos, por exemplo. Assim, relações tidas como assuntos sólidos são processos incertos e abertos que não podem ser reduzidos a um estado objetivo e acabado (Law, 1992, 1999). A exposição dessas relações por meio de controvérsias (Venturini, 2010a) mostra, por exemplo, como a governança organizacional e as relações entre os atores mudam ao longo do tempo (Michaud, 2014).

0 relacionalismo proposto pela ANTi-história sugere que as relações entre os atores em uma rede dão sentido a eventos passados e promovem engajamento político (Durepos \& Mills, 2017), tornando as questões controversas (Secord \& Corrigan, 2017). A resposta para a pergunta "Como o passado foi transformado em história?" é trazida à tona (Durepos \& Mills, 2018) pelo "olhar para a política de representação do passado rastreando atores simetricamente (tratando cada um com a mesma curiosidade) e trazendo à tona o passado como história em sua multiplicidade" (Durepos, Mills, \& Weatherbee, 2012, p. 269). Traçar a composição das redes (Durepos et al., 2012) permite aos pesquisadores passarem de fatos sociais tidos como certos para histórias alternativas explicando o surgimento deles (Foster, Mills, \& Weatherbee, 2014).

\section{Princípio de simetria}

As práticas de ordenação social resultam não apenas de ações humanas, mas também de associações entre humanos e não humanos (Latour, 2005). Por trás dessa ideia, está o princípio da simetria, que consiste em analisar atores humanos e não humanos nos mesmos termos analíticos (Latour, 1987; Latour \& Woolgar, 1986; Law, 1987). As controvérsias nas quais os atores estão engajados são uma ferramenta analítica simétrica potente, uma vez que sua análise requer que os estudiosos considerem todos os traços disponíveis do efeito dos atores (Venturini, 2010a).

O pressuposto é uma das ontologias planas na constituição de redes e controvérsias. Como a ação é resultado de entidades associadas (Latour, 2005), vários elementos, como ratos e pulgas (Anderson, 1974; Hinnebusch, 1997) - normalmente deixados de fora da análise organizacional -, podem participar da produção da história (Bettin \& Mills, 2018) e estar envolvidos em diferentes controvérsias (Secord \& Corrigan, 2017). É por meio de controvérsias que a heterogeneidade aparece com mais clareza. Nesse sentido, espera-se que múltiplas narrativas do passado sejam representadas por atores (Corrigan, 2016). Portanto, a realidade diz respeito à multiplicidade ( $\mathrm{Mol}, 2002)$, sendo mais do que um ao mesmo tempo que é menos do que muitos (Law, 2004; Mol, 1999). As histórias produzem realidades.

Multiplicidade: mais de um, menos do que muitos

A multiplicidade está relacionada às práticas que retratam uma realidade específica (Mol, 2002). Diferentes práticas produzem diferentes realidades (Law, 2004). Portanto, as realidades históricas são consequências das muitas pessoas e artefatos que compõem uma prática organizacional (Corrigan, 2016), bem como a forma como esses elementos são manipulados para criar múltiplas narrativas sobre o passado (Foster, Coraiola, Suddaby, Kroezen, \& Chandler, 2017). Quando narrativas concorrentes enquadram situações em termos diferentes, a controvérsia em torno de uma questão específica emerge, com suposições, procedimentos de rotina e pontos de argumentos sendo questionados (Scott et al., 1990).

Durepos e Mills (2018) afirmam que a realidade histórica é mais do que singular porque diferentes - mas não infinitas e independentes - versões do passado podem ser incorporadas por meio de práticas distintas. Ao mesmo tempo, a realidade histórica é, em alguns aspectos, menos do que infinita em suas possibilidades porque, embora os atores tenham diferentes perspectivas e visões do passado, essas perspectivas têm pontos de referência comuns (Durepos \& Mills, 2018). Uma parte da história pode ser contada em termos de reis, rainhas e elites; batalhas e vitórias; vencedores e perdedores; ou histórias de pessoas, mulheres e subalternos. A abordagem da ANTi-história leva essa ideia a sério e mostra que o trabalho histórico implica a representação de um conjunto de histórias produzidas por vários atores.

Os atores às vezes discordam uns dos outros, trazendo diferentes relevâncias e interesses ao contar a história, resultando em controvérsias (Latour, 2005; Venturini, 2010a). Portanto, a ANTi-história investiga as múltiplas representações observadas nas práticas dos atores (Kivijarvi et al., 2018) para permitir que realidades alternativas passem a existir. Presumir que o 
conhecimento da realidade é múltiplo implica uma questão política (Law, 2004; Mol, 1999) sobre qual realidade deve ser adotada. A melhor resposta para essa questão não é "tomar partido", mas desvendar analiticamente as controvérsias, como são constituídas e quais são os pressupostos que enquadram as diferentes posições (Yaneva, 2012).

\section{Conceitos para prática}

\section{Tradução}

A realidade social é obstinada, mas não imutável. Suas relações, equivalências e diferenças surgem por meio de atos de tradução. A tradução pode tornar coisas diferentes equivalentes (Law, 1999), transformando-as por meio da combinação de interesses em um único foco composto (Latour, 1999). É assim que as metas organizacionais se tornam evidentes, por exemplo, ao traduzir interesses que motivam as pessoas a agirem de modo diferente, mudarem de direção e se moverem de um lugar para outro em um objeto focalmente coletivo (Latour, 1987). Essa tradução é sempre contingente e local (Law, 1992).

Do ponto de vista histórico, entender como ocorre a transformação é importante. Assim, a ANTi-história foca as práticas pelas quais as relações realizam a história (Bettin \& Mills, 2018) e criam conhecimento do passado, moldando nossa visão do objeto de estudo (Kivijarvi et al., 2018). Relatos e narrativas históricas sobre o passado que parecem oferecer uma versão sólida, única e confiável da realidade devem ser vistos com desconfiança (Durepos \& Mills, 2018): tal concordância mascara os processos de sua produção. Como Laclau e Mouffe (1985) argumentam, a hegemonia consiste precisamente em tais práticas, e não no conteúdo substantivo que elas sustentam. A tradução envolve políticas de atores-redes, assim como argumentado por Secord e Corrigan (2017), de modo que "o conhecimento histórico está situado em práticas oficiais que ocultam traduções e estratégias políticas que permitem que atores-redes atuem como um" (p. 94).

\section{Política dos atores-redes}

A ANTi-história nos ajuda a mostrar o trabalho (Weatherbee, Durepos, Mills, \& Mills, 2012) realizado pela política de atoresredes, por meio do qual os atores buscam construir uma interpretação imutável do passado (Durepos et al., 2008), estabelecendo o domínio de uma determinada história (Durepos et al., 2012). Redes de atores são formadas por interesses políticos
(Alcadipani \& Hassard, 2010; Mol, 2002), portanto “o passado é visto como composto por atores que têm a capacidade de alterar o curso de outros atores" por meio da inclusão de elementos heterogêneos (Durepos \& Mills, 2012b, p. 711). A tradução de interesses, às vezes divergentes e contraditórios (Latour, 1999), leva os atores a se engajarem na política de atores-redes, criando uma interpretação do passado que pode ser considerada durável (Durepos \& Mills, 2012b).

Segundo Mol (2002), o "real” está implicado no "político", tornando a realidade algo não fixo (Alcadipani \& Hassard, 2010). Consequentemente, retratar uma realidade em vez de outra torna-se uma questão política: qualquer relato da realidade pode ocultar, encobrir ou deslocar possíveis versões alternativas (Law, 2004). Ao traçar a política das redes de atores, a ANTihistória busca explicitá-las (Durepos et al., 2008). A criação da história ocorre por meio de interpretações diversas e distintas da realidade, e contabilizá-las não é um processo tranquilo e estável (Kivijarvi et al., 2018), gerando controvérsias entre os atores envolvidos em sua produção. Portanto, quando abordamos a política de redes de atores, devemos falar sobre controvérsias.

\section{PROPOSTA DE MÉTODO}

\section{Critérios para escolher uma controvérsia}

A partir de Venturini (2010a, 2010b) e Hussenot (2014), indicamos alguns critérios utilizados na escolha de controvérsias para estudar o passado e analisar como os relatos históricos são criados. Ressalta-se que os quatro critérios elaborados por Venturini (2010a) para o estudo das controvérsias tecnocientíficas e adaptados por Hussenot (2014) para a investigação da controvérsia gerencial indicam o que os pesquisadores devem evitar em vez de favorecer. Mudamos a polaridade de três critérios para a direção oposta originalmente sugerida pelos autores. Ao invés de evitar "controvérsias passadas, frias e ocultas", recomendamos aceitá-las. Em relação ao quarto critério (evitar controvérsias sem limites), nós o enunciamos de modo diferente. Sugerimos que os pesquisadores "tomem cuidado com as controvérsias sem limites". Considerando a natureza da pesquisa da ANTi-história, ou seja, "uma abordagem crítica alternativa para fazer história nos estudos de gestão e organização" (Durepos \& Mills, 2017, p. 53), a modificação era necessária. A seguir, detalharemos cada um dos critérios, explicando nossa escolha por alterar a recomendação de utilizar três critérios e por modificar o quarto como forma de alerta. 
Primeiro critério: aceitar controvérsias do passado

Venturini (2010a) e Hussenot (2014) sugerem que os pesquisadores devem evitar as controvérsias do passado. Segundo Hussenot (2014), o objetivo de evitar as controvérsias do passado é evitar que os pesquisadores percam a compreensão do significado das controvérsias à medida que os atores produzem novas interpretações ao longo do tempo. No entanto, os processos de criação de sentido responsáveis por produzir conhecimento do passado devem ser investigados (Hartt, Mills, Mills, \& Corrigan, 2014), a fim de expor o que é tido como certo como fato histórico (Durepos et al., 2008). Venturini (2010a) argumenta que, se uma controvérsia passada chegou a um acordo e foi encerrada, ela carece de interesse, razão pela qual ele afirma que os pesquisadores devem evitar controvérsias anteriores. No entanto, o status de qualquer controvérsia nunca é definitivo (Mol, 1999) e pode ser representado de outra forma (Law, 2004). O aparente encerramento de uma controvérsia pode ser um meio pelo qual vozes divergentes foram silenciadas (Foster et al., 2017) e um fenômeno foi “colocado em uma caixa preta" (Latour, 1987).

Embora Venturini (2010a) recomende evitar controvérsias do passado, ele enfatiza alguns pontos importantes. Em primeiro lugar, questões passadas podem fazer parte da investigação se o pesquisador for capaz de voltar "ao momento em que a controvérsia estava se desenrolando" (p. 264). Conforme amplamente demonstrado pelos ANTi-historiadores, voltar ao passado e fazer um relato rigoroso da história é possivel (por exemplo, Deal et al., 2018; Secord \& Corrigan, 2017). Em segundo lugar, mesmo uma controvérsia que tenha alcançado uma resolução "pode ser encerrada de muitas maneiras diferentes" (Venturini, 2010a, p. 268), ou seja, a realidade histórica é mais do que um e menos do que muitos (Durepos \& Mills, 2018). Ressaltamos que, se os pesquisadores pretendem compreender a realidade por meio de controvérsias, não devem evitar as controvérsias do passado, mas sim tentar trazê-las à tona por meio da associação de elementos heterogêneos.

\section{Segundo critério: aceitar controvérsias frias}

Segundo Venturini (2010a), situações em que os atores não estão atualmente em desacordo ou onde não há potencial de ruptura entre eles não favorecem a análise de controvérsias; é melhor observar debates acalorados para compreender as várias dimensões de uma controvérsia (Hussenot, 2014). 0 que foi uma controvérsia pode ter sido colocado em uma caixa preta devido a suposições dominantes que silenciavam vozes marginalizadas. É o caso da natureza não controversa do efeito Hawthorne durante grande parte do seu percurso, a qual pesquisas recentes desconstruíram ao retornar ao "caso arquivado" e vê-lo novamente por meio de materiais históricos (Busse \& Warner, 2017; Hassard, 2012; Mannevuo, 2018; Muldoon, 2017). A inspeção de uma questão supostamente fria pode revelar que o conhecimento do passado é um dado adquirido na história organizacional (Durepos \& Mills, 2012b; Durepos et al., 2008). Os sentimentos, significados e emoções dos atores (Hussenot, 2014) podem ter sido suprimidos da cena e ficar ocultos da vida organizacional cotidiana (Mannevuo, 2018). Controvérsias frias permanecem como uma barreira sobre vozes silenciadas e histórias não contadas (Kivijarvi et al., 2018) e podem ser ocultadas da história organizacional.

\section{Terceiro critério: aceitar controvérsias ocultas}

Venturini (2010a) e Hussenot (2014) recomendam que os pesquisadores evitem controvérsias ocultas. Concordamos que é difícil acessar questões confidenciais ou secretas (Venturini, 2010a), especialmente quando as organizações desejam preservar sua reputação (Hussenot 2014). No entanto, se os atores atuam ou se, de alguma forma, se associam, deixam alguns vestígios e informações que os pesquisadores podem usar para descrevê-los (Latour, 2005), mesmo que a controvérsia seja supostamente fria e tenha sido ocultada.

Considerando que as boas controvérsias são as mais intensas (Venturini, 2010a), os pesquisadores devem aceitar as controvérsias ocultas como um meio de dar vida à dinâmica organizacional e aos debates acalorados (Hussenot, 2014) de modo a expor as relações de poder, a política das redes de atores e mostrar a multiplicidade da realidade. Traçar relações de poder e mostrar como o conhecimento do passado é produzido e dado como certo é um dos objetivos da abordagem da ANTihistória (Corrigan \& Mills, 2012). As relações de poder podem ser mascaradas, enterrando as controvérsias e cobrindo-as com relações sociais naturalizadas, estabelecidas em estruturas institucionais, embutidas nas tecnologias ou enviesadas na criação histórica. Como Mannevuo (2018) sugere, as configurações das organizações "sempre têm fraturas que podem abrir possibilidades para leituras reparativas do processo de formação de trabalhadores e, assim, revisar teorias excessivamente deterministas de opressão e vulnerabilidade" (p. 1243), o que ela argumenta ter sido o caso da pesquisa histórica conduzida na Sala de Testes de Montagem de Relés da planta Hawthorne da General Electric. 
Simon Kuper (2019) fornece outro exemplo adequado ao mostrar como a adesão à Oxford Union na década de 1980 prefigurava a política do Brexit nos dias atuais. Como ele descreve, "você vira as páginas de jornais de estudantes amarelecidos de 30 anos atrás, e lá estão eles, reconhecidamente os mesmos rostos que dominam as notícias britânicas de hoje”. Johnson, Gove, Rees-Mogg, Hunt e Cameron saíram sem esforço de suas escolas de elite (na maioria dos casos, Eton) para um meio no qual as habilidades de debate consistiam, em grande parte, na capacidade de falar com humor sobre algo de que se tinha pouco conhecimento sem sentir a necessidade de ganhar o debate. Estilo acima do conteúdo, retórica e sagacidade acima da razão e da evidência: esses eram os atributos que marcavam a rede de atores que se tornaria o círculo governante do Brexit no governo.

Quarto critério: ter cuidado com controvérsias sem limites

Venturini (2010a) e Hussenot (2014) sugerem que os pesquisadores devem evitar controvérsias sem limites. Não sugerimos evitar totalmente esse tipo de controvérsia, pois traçar a extensão de uma rede de atores relacionada a uma controvérsia é uma escolha do pesquisador baseada no interesse em abordar um determinado período no relato histórico ou no qual a rede de atores em estudo está situada (Law, 1987). Além disso, a extensão de uma controvérsia depende de sua complexidade e abrangência (Venturini, 2010a). Não recomendamos, entretanto, aceitar controvérsias ilimitadas indiscriminadamente, mas sim que, ao escolher uma controvérsia envolta em muito debate, exigindo muito trabalho e tempo, os pesquisadores estejam cientes da disponibilidade de recursos (Venturini, 2010a) e dos limites textuais dos gêneros. Conforme apontado por Latour (2005), “qualquer método depende do tamanho e do tipo de texto que você prometeu entregar [...] escrever textos tem tudo a ver com método" (p. 148, itálico no original).

Uma abordagem útil para lidar com essas questões é tomar o conceito da Teoria ator-rede (TAR), que entende o ator como qualquer coisa que faz a diferença, modificando o estado das coisas (Latour, 2005; Mol, 2010), e o utilizar na delimitação do escopo da rede de atores envolvidos na controvérsia. Conforme afirma Law (1987), “o escopo da rede em estudo é determinado pela existência de atores que são capazes de fazer sentir a sua presença individual nela" (p. 131). Essa abordagem está alinhada com a abordagem da ANTi-história por entender os atores como elementos capazes de alterar as ações de outros atores por meio de associações (Durepos \& Mills, 2012b). Segundo Latour (2005), os atores deixarão alguns rastros, direta ou indiretamente, mesmo que sejam silenciados ou reprimidos, gerando oportunidades para inspecionar elementos de uma rede que costumam ser ignorados (Law, 1992). Tendo esses critérios em mente, veremos, a seguir, as cinco etapas de pesquisa implicadas no uso de pressupostos e práticas da ANTi-história.

\section{Etapas de pesquisa}

Nesta seção, apresentaremos as cinco etapas úteis para os pesquisadores da ANTi-história: a primeira é identificar a controvérsia relacionada ao fenômeno em análise; a segunda é mapear a rede de atores envolvida na controvérsia ao longo do tempo; a terceira é rastrear a prática de tradução ao longo da história; a quarta é identificar a política dos atores-redes; a quinta é descrever as múltiplas realidades sendo desempenhadas na prática pelos atores. Essas etapas não devem ser vistas de modo linear, pois muitas delas ocorrem simultaneamente.

\section{Amostragem: como identificar controvérsias.} Conforme mencionado anteriormente, quando apresentamos os critérios para a escolha de controvérsias, é útil identificar uma controvérsia emergente e viva (Hussenot, 2014; Venturini, 2010a). No entanto, em vez de ignorar controvérsias frias, os pesquisadores devem inspecioná-las em busca de vozes silenciadas e reprimidas marginalizadas por relações de poder, cujos efeitos podem se tornar visíveis como "traços suprimidos" (Hartt et al., 2014, p. 14). As controvérsias expõem relações ocultas e heterogêneas (Venturini, 2010a) na rede de atores do relato histórico. À medida que a controvérsia se desenvolve, a heterogeneidade da interpretação de um objeto apresenta-se mais claramente conforme os atores envolvidos discutem e se posicionam em relação ao suposto objeto (Latour, 1987) de contestação.

Para identificar o que é ou não controvérsia, os pesquisadores devem buscar ideias ou práticas tidas como certas no passado, mas que estão sendo questionadas mais recentemente (Venturini, 2010a). Ao contrário dos conflitos de relacionamento pontuais ou conflito de tarefas (Jehn, 1995), as controvérsias históricas desencadeiam uma variedade de questões sucessivas (Hussenot, 2008) relacionadas ao passado e à facticidade da produção de conhecimento (Durepos \& Mills, 2018). A tensão entre narrativas e relatos distintos é o que importa, 
pois evidencia uma ruptura inicial entre os atores (Bettin \& Mills, 2018). Identificada a controvérsia, abre-se caminho para que o pesquisador descubra quem foram os atores e, posteriormente, trace as diferentes narrativas históricas criadas por eles nas divergências. Assim, o próximo passo é mapear a rede de atores da controvérsia.

\section{Escaneamento do terreno: como mapear a rede de} atores. Depois que surge uma controvérsia, uma rede de atores forma-se em torno dela, tornando-se “as configurações fugazes onde os atores estão renegociando os laços de velhas redes e o surgimento de novas redes está redefinindo a identidade dos atores "(Venturini, 2010a, p. 264). As controvérsias envolvem todos os tipos de atores (Hussenot, 2014; Venturini, 2010a): aqueles centrais e periféricos (Corrigan \& Mills, 2012), atuantes não corpóreos (Hartt et al., 2014), humanos e não humanos (Secord \& Corrigan, 2017) e profissionais e historiadores (Kivijarvi et al., 2018). Considerando que a análise da controvérsia é baseada no princípio da simetria (Callon, 1986), mapear uma rede de atores exige estar aberto a todas as perspectivas e incluir tantos pontos de vista quanto possível (Venturini, 2010b).

Dessa forma, uma rede de atores pode ser mapeada por meio de três parâmetros que assumem o ponto de vista dos atores: representatividade, influência e interesse (Venturini, 2010b). Esses parâmetros são úteis para enquadrar a escolha do pesquisador sobre a extensão da rede de atores a ser mapeada. Um ponto de vista é considerado representativo quando tem apoio substancial de atores que têm argumentos em comum. Nessa situação, as falas desse grupo merecem atenção especial do pesquisador. Para mapear a rede de atores, é importante que os pesquisadores identifiquem os atores cujas declarações geram controvérsia. As visões minoritárias não devem ser desconsideradas, como veremos adiante, "porque a representatividade é muito mais uma questão de pesar do que de contar” (Venturini, 2010b, p. 798).

Alguns pontos de vista têm mais influência do que outros. Enquanto uma controvérsia está em cursos, atores vão competir para ocupar posições influentes "que lhes dão o poder de afetar as ações de outros atores [...] porque, gostem ou não, eles terão melhores chances de moldar controvérsias" (Venturini, 2010b, p. 798). Pontos de vista influentes dizem respeito não apenas ao número de aliados que atraem, mas também ao recrutamento de apoios proeminentes, aumentando, assim, a chance de sucesso. O mapeamento da rede de atores exige que o pesquisador trace no tempo as trilhas utilizadas pelos atores para se posicionar em um ponto favorável capaz de recrutar apoiadores de peso.

A controvérsia obrigatoriamente depende de minorias disputando e discordando de relatos da maioria: "São as minorias discordantes que trazem controvérsias ao se recusar a se adequar ao convencional e reabrir as caixas pretas" (Venturini, 2010b, p. 798) de relatos históricos. Os pontos de vista marginais e das minorias articulam perspectivas silenciadas ou reprimidas que são úteis para questionar o que é dado como certo e mostrar versões alternativas da realidade marginalizada por atores poderosos.

\section{Traçar: como desenhar o processo de tradução.} Mapear a rede de atores envolvida em uma controvérsia ao longo do tempo é uma etapa que torna os atores e as conexões mais visíveis. No entanto, conforme observado por Bettin e Mills (2018, p. 70), fazer história não se limita a rastrear a associação de humanos e não humanos, "mas também inclui se preocupar sobre como os atores se relacionam, como se conectam e desconectam, e como eles alcançam alinhamentos tão fortes" para criar história. Esses movimentos entre os atores são um efeito dos processos de tradução e, em certa medida, são resultado das controvérsias (Hussenot, 2014).

Callon (1986) descreveu a tradução como composta por quatro etapas: problematização, interesse, engajamento e mobilização de aliados. Problematização refere-se a um sistema de alianças ou associações estabelecidas entre entidades para definir sua identidade e objetivos e para criar um ponto de passagem obrigatório que todos os atores devem aceitar para alcançar o que desejam (ver Clegg, 1989). Em controvérsias, isso significa que as associações e oposições criadas em torno de uma questão específica determinam as posições dos atores e da estrutura da rede ao longo do processo e fluxo de sua evolução (Venturini, Rici, Mauri, Kimbell, \& Meunier, 2015).

O interessamento é representado por ações realizadas pelos atores "para impor e estabilizar os outros atores definidos por meio de sua problematização" e construir dispositivos para protegê-los de outros atores "que querem definir suas identidades de outra forma” (Callon, 1986, pp. 71-72). Embora o sucesso do interessamento seja influenciado pela etapa anterior e seus sistemas de alianças, ele nunca está assegurado. Portanto, os atores devem ser engajados. 
O engajamento corresponde à atribuição de papéis inter-relacionados para a criação de alianças entre os atores, resultante de múltiplas negociações em torno de uma solução proposta. A discordância suscitada por uma controvérsia nesta etapa explicita não apenas os comportamentos e expectativas dos atores, mas também as principais práticas e regras organizacionais (Hussenot, 2014).

Por fim, a mobilização é a etapa em que os atores aceitam um objetivo específico, há uma coalizão dominante de elites que estão bem interligadas e têm um papel claro na rede. Nesse momento, um ator central passa a ser um porta-voz influente, representando uma rede de interesses que dá voz a todos aqueles silenciados durante a formação da rede. As diversas entidades atuam em unidade, como uma rede de atores, por meio de um porta-voz representativo. Nesta fase, a controvérsia termina no compromisso de uma ordem negociada (Venturini, 2010a) cujo resultado passa a ser legitimado (Lanzara \& Patriotta, 2001) como a história organizacional oficial.

Essas diferentes etapas do processo de tradução podem ser úteis para um ANTi-historiador na investigação de controvérsias, mas sugerimos que não sejam usadas de maneira linear e mecânica, pois podem se sobrepor e não têm limites claros (Callon, 1986).

4. Rotulagem: a política dos atores-redes. As controvérsias da rede de atores são decididas por relações e práticas de poder (Law, 2004; Mol, 2002; Venturini, 2010a). Algumas posições tornam-se mais influentes à medida que alguns atores se tornam aptos a moldar controvérsias (Venturini, 2010b). 0 que é considerado conhecido envolve a manipulação do fluxo de possíveis conhecimentos (Mol, 1999) que passam a fazer parte da criação da história (Bettin \& Mills, 2018). Tomando essa ideia como ponto de partida, Durepos e Mills (2018) afirmam que, "se existem diferentes versões do passado adotadas como história, e essas são diferentes versões da realidade, então a questão é qual versão adotar" (p. 444). Existe uma política de redes de atores-redes, isto é, o engajamento de atores (especialistas, entrevistados, historiadores, ideias, documentos, artefatos, arquivos) conforme eles se inserem na rede, alteram o curso de ação e instilam uma versão da realidade favorável a um grupo específico (Durepos \& Mills, 2012b).

Nessa etapa, o pesquisador identifica o que move (Blum \& McHugh, 1971) os atores envolvidos na controvérsia. O foco está no que os move a investir seu tempo e recursos para persuadir os outros a criarem uma meta, se conectarem, aceitarem um papel e serem representados por um ator central. Dessa forma, a análise da controvérsia mostra as implicações sociais de suposições tidas como certas que assumem uma inércia relativa sendo desafiadas por motivações para a ação (Scott et al., 1990, p. 474).

Além disso, uma tarefa importante é investigar como algumas motivações são reprimidas e silenciadas em uma situação controversa, especialmente pelo resultado de controvérsias passadas que se enraízam nas estruturas das organizações, de processos e relacionamentos, formando pontos nodais necessários (Lanzara \& Patriotta, 2001). Os meios de representação dos eventos passados que levaram à integração presente (narrativa, escrita ou artefato) afetam seu significado. De acordo com Durepos e Mills (2018), “a história é o resultado da sócio-política de diferentes conglomerados de atores (humanos, não humanos e não corporais) à medida que transformam um sentido do passado" (p. 437, ver Deal et al., 2018; Hartt et al., 2014), portanto não é sensato limitar as fontes investigadas.

\section{Descrever a realidade múltipla e a relação de poder.}

Após realizar as etapas anteriores, o pesquisador poderá realizar a etapa final, de descrever a multiplicidade na criação da história. Identificar atores excluídos e trazer à tona eventos/ações ocultos pode revelar múltiplas realidades passadas. Conforme mostrado por Mol (2002), diferentes realidades são representadas como resultado de distintas práticas e compromissos após a resolução de uma controvérsia (Venturini, 2010a). Quando uma realidade está em uma caixa preta, não podemos ver os atores cuja associação a um ator central é menos visível, a menos que sejam revelados por uma controvérsia (Callon, 1989). Assim, nesta etapa, os pesquisadores devem estar atentos às práticas cotidianas dos atores que atuam em realidades visíveis e menos visíveis, pois é delas que surge a história (Bettin \& Mills, 2018).

A análise da controvérsia no estudo do passado é uma ferramenta capaz de mostrar que as controvérsias em torno da criação da história podem ser encerradas de diferentes maneiras (Venturini, 2010a), e que a realidade pode se apresentar de outra forma (Law, 2004). Levar a sério as premissas de multiplicidade ajuda a "minar qualquer noção de que o passado é fixo e imutável, evitando o encerramento enquanto permanece sempre aberto à revisão" (Maclean et al., 2016, p. 627). Ao abordar a controvérsia, estamos considerando a política democrática de pesquisa como um exercício sério de conjecturas e refutações - a pesquisa como política por outros meios, e não sua concepção como um processo ordenado de acumulação de conhecimentos mais certos. Em vez 
disso, seguindo os passos de Popper (2014), tomamos como direção o dissenso, a negação e a democracia.

Focar as rupturas das experiências dos atores do cotidiano é uma oportunidade para entender a dinâmica organizacional (Hussenot, 2014) e como associações e alianças são construídas para resolver uma realidade específica e marginalizar outras, nem sempre de modo intencional. Portanto, para identificar a multiplicidade, sugerimos que os pesquisadores busquem narrativas, documentos, artefatos ou eventos que forneçam algumas pistas para os potenciais desacordos a respeito da história organizacional ou do conhecimento do passado e das práticas realizadas pelos atores. A controvérsia organizacional diz respeito a diferenças cujo desdobramento exibe distribuições crescentes de poder (Venturini, 2010a). ANTi-historiadores "obscurecem" o trabalho constante dos atores em estabelecer conexões, disputar e negociar quaisquer que sejam as questões em jogo. Após a ação, as multiplicidades proliferam empiricamente.

\section{Exemplo prático}

Um exemplo de história do presente considerando a cartografia moderna dos termos das controvérsias seria o tema do ambientalismo e das mudanças climáticas, bem como os diversos objetos utilizados para representá-lo: incêndios na Amazônia, Califórnia e Austrália; derretimento do gelo na Groenlândia, na Antártica e nos Alpes; inundações de proporções gigantescas no Reino Unido, nos Estados Unidos e em Bangladesh. Assim, pode-se pensar na negociação das mudanças climáticas como uma potencial controvérsia a ser investigada em Estudos de Gestão e Organização (etapa 1: amostragem). Uma vez que uma negociação específica de mudança climática é identificada como uma controvérsia, o pesquisador deve identificar quem são os atores (líderes nacionais, ONGs, corporações transnacionais) e traçar as diferentes narrativas históricas produzidas por eles e que atualmente estão em desacordo (argumentos favoráveis versus argumentos contrários). Com base em uma análise do ambientalismo e suas múltiplas facetas ao longo da história, Bothello e Salles-Djelic (2018) identificam vários atores internacionais (por exemplo, organizações intergovernamentais, grupos empresariais e cientistas) responsáveis por criar iniciativas e narrativas relacionadas a esse tópico ao longo do tempo. Essa prática de escaneamento ajuda os pesquisadores a gerarem uma imagem mais ampla do terreno, a qual será rastreada na próxima etapa (etapa 2: escaneamento). No entanto, ainda é necessário entender como as relações entre os atores acontecem no que diz respeito à negociação das mudanças climáticas, como e se elas se conectam e quais são os resultados dessas relações. Para traçar a prática tradutória da negociação de mudanças climáticas, é preciso descrever como se dá a relação entre pontos de vista contraditórios, porque as controvérsias são foco de disputas e debates, exigindo a construção e mobilização de alianças entre atores heterogêneos (Venturini, 2010b). Pode ser assim que as organizações se esforçam para gerenciar seus efeitos sobre as fronteiras planetárias (Bothello \& Salles-Djelic, 2018) na era do Antropoceno (Heikkurinen, Clegg, Pinnington, Nicolopoulou, \& Caraz, 2020). Mais prosaicamente, poderia ser uma questão das relações entre tecnologia e prática de trabalho (Hussenot, 2008), o papel dos objetos de mediação (Hussenot \& Missonier, 2010) e os aspectos sociais, culturais e políticos de uma inovação (Callon, 1989) (etapa 3: rastreamento).

Evidentemente, é importante considerar as relações de poder (Mol, 2002), pois certas posições de atores na rede têm maiores habilidades para influenciar a direção da controvérsia. É nesse sentido que Venturini (2010b), ao tratar das controvérsias climáticas, afirma que diferentes pesos devem ser dados a diferentes atores (Painel sobre Mudanças Climáticas, Coalizão Global do Clima) na negociação de um acordo sobre aquecimento global com uma chance mínima de sucesso, uma vez que as perspectivas são apoiadas de modos diferentes. Para Bothello e Salles-Djelic (2018), é o que ocorre quando as organizações tentam incorporar o discurso ambientalista. Os atores organizacionais mobilizam e defendem conceitos diferentes em relação a suposições ideológicas específicas que "evocam implicações normativas contrastantes em, por exemplo, agências públicas ou empresas com fins lucrativos" (p. 94). Além disso, os pesquisadores devem concentrar-se nas motivações que levam os atores a investir recursos para persuadir os outros da validade de seu ponto de vista. Por exemplo, algumas empresas investem muito dinheiro em responsabilidade ambiental, produtos verdes e pesquisa científica. Seria importante investigar como algumas vozes são reprimidas no processo contínuo de disputa. Por exemplo, a disseminação de memes nas redes sociais ridicularizando os defensores do meio ambiente (etapa 4: rotulagem).

Considerando as razões e perspectivas envolvidas na controvérsia, compreender quais são mais representativas e quais são silenciadas permite ao pesquisador articular a multiplicidade da criação da história. Bothello e Salles-Djelic (2018) ilustram essa situação ao afirmar que o ambientalismo não é homogêneo e atemporal porque é uma instituição historicamente construída e repleta de narrativas múltiplas. Segundo esses autores, diferentes rótulos estão associados ao ambientalismo, indicando 
que esse conceito não pode ser reduzido a uma única visão. Existem vários pontos de vista que apoiam o ambientalismo e as mudanças climáticas. No entanto, existem vários outros baseados, em argumentos razoáveis, que questionam alguns aspectos específicos do aquecimento global. Cada um deles gera implicações gerenciais específicas para organizações e tomadores de decisão. Eles também ser incluídos na rede de atores para mostrar que a realidade histórica é múltipla (Durepos, 2015). Eles podem coexistir, mas às vezes se chocam (etapa 5: descrever).

Isso, como inúmeros outros exemplos que poderiam ser dados, mostram que aceitar controvérsias na análise organizacional exige estar aberto para descrever e não simplificar sua multiplicidade e complexidade (Latour, 2005; Venturini, 2010a).

\section{Conclusão}

Nosso objetivo neste artigo foi desenvolver e propor um método para ANTi-historiadores usando a análise da controvérsia como ponto de partida. Considerando que o conhecimento do passado e a criação da história são atividades performativas, ou seja, são uma questão de prática, pretendemos aprofundar a pesquisa da ANTi-história, sugerindo um método para compreender a análise dos fenômenos que ela evoca. Ao fazê-lo, mostramos que o método da cartografia das controvérsias parece ser uma ferramenta útil para atingir esse objetivo. Vozes marginalizadas, silenciadas ou reprimidas podem vir à tona quando os pesquisadores procuram as rupturas causadas por discordâncias e conflitos que acontecem ao longo da vida organizacional e das práticas dos atores. Em consonância com Durepos e Mills (2018), concordamos que "a mudança de foco do conhecimento para a prática terá consequências na forma como abordamos a história" (p. 441). Portanto, mais do que um aprimoramento teórico, é necessário o desenvolvimento de métodos à altura do desafio colocado pela ANTi-história. O que foi dito acima serve como um palco no qual essa controvérsia pode se desenrolar.

\section{REFERÊNCIAS}

Alcadipani, R., \& Hassard, J. (2010). Actor-network theory, organizations and critique: Towards a politics of organizing. Organization, 17(4), 419-435. doi: 10.1177/1350508410364441.

Anderson, P. (1974). Lineages of the absolutist state. London, UK: New Left Books.

Bettin, C., \& Mills, A. J. (2018). More than a feminist: ANTi-Historical reflections on Simone de Beauvoir. Management \& Organizational History, 13(1), 65-85. doi: 10.1080/17449359.2018.1446835.
Blum, A. F., \& McHugh, P. (1971). The social ascription of motives. American Sociological Review, 36(1), 98-109. doi: 10.2307/2093510.

Booth, C., \& Rowlinson, M. (2006). Management and organizational history: Prospects. Management \& Organizational History, 1(1), 5-30. doi: 10.2307/2093510.

Bothello, J., \& Salles-Djelic, M.-L. (2018). Evolving conceptualizations of organizational environmentalism: A path generation account. Organization Studies, 39(1), 93-119. doi: 10.1177/0170840617693272.

Busse, R., \& Warner, M. (2017). The legacy of the hawthorne experiments: A critical analysis of the 'Human Relations School of Thought'. History of Economic Ideas, 5(2), 91-114. doi: 10.19272/201706102004.

Callon, M. (1986). Some elements of a sociology of translation: Domestication of the scallops and the fishermen of St. Brieuc Bay. In J. Law (Ed.), Power, action, and belief: A new sociology of knowledge? (pp. 196-223). London, UK: Routledge \& Kegan Paul.

Callon, M. (1989). Society in the making: The study of technology as a tool for sociological analysis. In W. E. Bijker, T. P. Hughes, \& T. Pinch (Eds.), The social construction of technological systems (pp. 83-103). Cambridge, USA: MIT Press.

Clegg, S. R. (1989). Frameworks of power. London, UK: Sage.

Coraiola, D. M., Suddaby, R., \& Foster, W. M. (2017). Mnemonic capabilities: Collective memory as a dynamic capability, RAE-Revista de Administração de Empresas, 57(3), 258-263. doi: 10.1590/so034 759020170306.

Corrigan, L. T. (2016). Accounting practice and the historic turn: Performing budget histories. Management \& Organizational History, 11(2), 77-98. doi: 10.1080/17449359.2015.1115743.

Corrigan, L. T., \& Mills, A. J. (2012). Men on board: Actor-network theory, feminism and gendering the past. Management \& Organizational History, 7(3), 251-265. doi: 10.1177/1744935912444357.

Deal, N. M., Mills, A. J., \& Mills, J. H. (2018). Amodern and modern warfare in the making of a commercial airline. Management \& Organizational History, 13(4), 373-396. doi: 10.1080/17449359.2018.1547647.

Durepos, G. (2015). ANTi-History: Toward amodern histories. In P. McLaren, A. J. Mills, \& T. Weatherbee (Eds.), The Routledge Companion to management and organizational history (pp. 153-180). New York, USA: Routledge.

Durepos, G., \& Mills, A. (2012a). ANTi-History: Theorizing the past, history, and historiography in management and organizational studies. Charlotte, USA: Information Age Publishing.

Durepos, G., \& Mills, A. J. (2012b). Actor-network theory, ANTi-history and critical organizational historiography. Organization, 19(6), 703 721. doi: 10.1177/1350508411420196.

Durepos, G., \& Mills, A. J. (2017). ANTi-History, relationalism and the historic turn in management and organization studies. Qualitative Research in Organizations and Management: An International Journal, 12(1), 53-67. doi: 10.1108/QROM-07-2016-1393.

Durepos, G., \& Mills, A. J. (2018). ANTi-History: An alternative approach to history. In C. Cassell, A. L. Cunliffe, \& G. Grandy (Eds.), The SAGE handbook of qualitative business and management research methods (pp. 431-449). California, USA: Sage.

Durepos, G., \& Mills, A. J., \& Mills, J. H. (2008). Tales in the manufacture of knowledge: Writing a company history of Pan American World Airways. Management \& Organizational History, 3(1), 63-80. doi: 10.1177/1744935908090998. 
Durepos, G., Mills, A. J., \& Weatherbee, T. G. (2012). Theorizing the past: Realism, relativism, relationalism and the reassembly of Weber. Management \& Organizational History, 7(3) 267-281. doi: $10.1177 / 1744935912444353$.

Durepos G, Shaffner EC, Taylor S. Developing critical organizational history: Context, practice and implications. Organization. October 2019. doi:10.1177/1350508419883381

Foster, J., Mills, A. J., \& Weatherbee, T. (2014). History, field definition and management studies: The case of the New Deal. Journal of Management History, 20(2), 179-199. doi: 10.1108/JMH-02-20130011.

Foster, W. M., Coraiola, D. M., Suddaby, R., Kroezen, J., \& Chandler, D. (2017). The strategic use of historical narratives: A theoretical framework. Business History, 59(8), 1176-1200. doi: 10.1080/00076791.2016.1224234.

Hartt, C., Mills, A. J., Mills, J. H., \& Corrigan, L. T. (2014). Sense-making and actor networks: The non-corporeal actant and the making of an Air Canada history. Management \& Organizational History, 9(3), 288 304. doi: $10.1080 / 17449359.2014 .920260$.

Hassard, J. S. (2012). Rethinking the Hawthorne Studies: The Western Electric research in its social, political and historical context. Human Relations, 65(11), 1431-1461. doi: 10.1177/0018726712452168.

Heikkurinen, P., Clegg, S., Pinnington, A. H., Nicolopoulou, K., \& Alcaraz, J. M. (2019). Managing the Anthropocene: Relational Agency and Power to Respect Planetary Boundaries. Organization \& Environment. https://doi.org/10.1177/1086026619881145

Hinnebusch, B. J. (1997). Bubonic plague: A molecular genetic case history of the emergence of an infectious disease. Journal of Molecular Medicine, 75(9), 645-652. doi: 10.1007/s001090050148.

Hussenot, A. (2008). Between structuration and translation: An approach of ICT appropriation. Journal of Organizational Change Management, 21(3), 335-347. doi: 10.1108/09534810810874813.

Hussenot, A. (2014). Analyzing organization through disagreements: The concept of managerial controversy. Journal of Organizational Change Management, 27(3), 373-390. doi: 10.1108/JOCM-01-20120006.

Hussenot, A., \& Missonier, S. (2010). A deeper understanding of evolution of the role of the object in organizational process: The concept of "mediation object". Journal of Organizational Change Management, 23(3), 269-286. doi: 10.1108/09534811011049608.

Jehn, K. A. (1995). A multimethod examination of the benefits and detriments of intragroup conflict. Administrative Science Quarterly, 40(2), 256-282. doi: 10.2307/2393638.

Kivijarvi, M., Mills, A. J., \& Mills, J. H. (2018). Performing Pan American Airways through coloniality: An ANTi-History approach to narratives and business history. Management \& Organizational History, 14(1), 33-54. doi: $10.1080 / 17449359.2018 .1465825$.

Kuper, S. (2019). How Oxford university shaped Brexit: And Britain's next prime minister. Financial Times, 18 September. Retrieved from https://www.ft.com/content/85fc694c-9222-11e9-b7ea$60 \mathrm{e} 35 \mathrm{ef} 678 \mathrm{~d} 2$

Laclau, E., \& Mouffe, C. (1985). Hegemony and socialist strategy: Towards a radical democratic politics. London, UK: Verso.
Lanzara, G. F., \& Patriotta, G. (2001). Technology and the courtroom: An inquiry into knowledge making in organization. Journal of Management Studies, 38(7), 943-971. doi: 10.1111/1467-6486.00267.

Latour, B. (1987). Science in action: How to follow scientists and engineers through society. Cambridge, USA: Harvard University Press.

Latour, B. (1999). Pandora's hope: Essays on the reality of science studies. Cambridge, USA: Harvard University Press.

Latour, B. (2005). Reassembling the social: An introduction to actornetwork-theory. Oxford, UK: Oxford University Press.

Latour, B., \& Woolgar, S. (1986). Laboratory life: The construction of scientific facts. Princeton, USA: Princeton University Press.

Law, J. (1987). Technology and heterogeneous engineering: The case of Portuguese expansion. In W. E. Bijker, T. P. Hughes, \& T. Pinch (Eds.), The social construction of technological systems: New directions in the sociology and history of technology (pp. 111-134). Cambridge, USA: MIT Press.

Law, J. (1992). Notes on the theory of the actor-network: Ordering, strategy and heterogeneity. Systems Practice, 5(4), 379-393. doi: 10.1007/BFo1059830.

Law, J. (1994). Organizing modernity. Oxford, UK: Blackwell.

Law, J. (1999). After ANT: Complexity, naming and topology. In J. Law, \& J. Hassard (Eds.), Actor network theory and after (pp. 1-14). Oxford, UK: Blackwell.

Law, J. (2004). After method: Mess in social science research. London, UK, New York, USA: Routledge.

Maclean, M., Harvey, C., \& Clegg, S. R. (2016). Conceptualizing historical organization studies. Academy of Management Review, 41(4), 609632. doi: 10.5465/amr.2014.0133.

Maclean, M., Harvey, C., \& Clegg, S. R. (2017). Organization theory in business and management history: Present status and future prospects. Business History Review, 91, 457-481. doi: 10.1017/ So007680517001027.

Mannevuo, M. (2018). The riddle of adaptation: Revisiting the Hawthorne studies. The Sociological Review, 66(6), 1242-1257. doi: $10.1177 / 0038026118755603$.

Michaud, V. (2014). Mediating the paradoxes of organizational governance through numbers. Organization Studies, 35(1), 75-101. doi: $10.1177 / 0170840613495335$.

Mills, A. J., \& Durepos, G. (2010). ANTi-history. In A. J. Mills, G. Durepos, \& E. Weibe (Eds.), Encyclopedia of case study research (pp. 26-29). California, USA: Sage.

Mills, A. J., Suddaby, R., Foster, W. M., \& Durepos, G. (2016). Revisiting the historic turn 10 years later: Current debates in management and organizational history - an introduction. Management \& Organizational History, 11(2), 67-76. doi: 10.1080/17449359.2016.1164927.

Mol, A. (1999). Ontological politics: A word and some questions. In J. Law, \& J. Hassard (Eds.), Actor network theory and after (pp. 74-89). Oxford, UK: Blackwell Publishers.

Mol, A. (2002). The body multiple: Ontology in medical practice. Durham, USA: Duke UP.

Mol, A. (2010). Actor-network theory: Sensitive terms and enduring tensions. Kölner Zeitschrift für Soziologie und Sozialpsychologie, 50(1), 253-269. 
Muldoon, J. (2017). The Hawthorne studies: An analysis of critical perspectives, 1936-1958. Journal of Management History, 23(1), 7494. doi: 10.1108/JMH-09-2016-0052.

Myrick, K., Mills, J. H,, \& Mills, A J. (2013). History-making and the Academy of Management: An ANTi-History perspective. Management \& Organizational History, 8(4), 345-370. doi: 10.1080/17449359.2013.821662.

Ocasio, W., Mauskapf, M., \& Steele, C. W. J. (2016). History, society, and institutions: The role of collective memory in the emerging and evolution of societal logics. Academy of Management Review, 41(4), 676-699. doi: 10.5465/amr.2014.0183.

Popper, K. (2014). Conjectures and refutations: The growth of scientific knowledge. London, UK: Routledge.

Scott, P., Richards, E., \& Martin, M. (1990). Captives of controversy the myth of the neutral social researcher in contemporary scientific controversies. Science, Technology, \& Human Values, 15(4), 474-494. doi: $10.1177 / 016224399001500406$.
Secord, P., \& Corrigan, L. T. (2017). ANTi-History and the entrepreneurial work of privateers. Qualitative Research in Organizations and Management: An International Journal, 12(2), 94-110. doi: 10.1108/ QROM-06-2016-1389.

Venturini, T. (2010a). Diving in magma: How to explore controversies with actor-network theory. Public Understanding of Science, 19(3), 258-273. doi: 10.1177/0963662509102694.

Venturini, T. (2010b). Building on faults: How to represent controversies with digital methods. Public Understanding of Science, 21(7), 796812. doi: $10.1177 / 0963662510387558$.

Venturini, T., Ricci, D., Mauri, M., Kimbell, L., \& Meunier, A. (2015). Designing controversies and their publics, Design Issues, 31(3), 7487. doi: 10.1162/DESI_a_00340.

Weatherbee, T. G., Durepos, G., Mills, A., \& Mills, J. H. (2012). Theorizing the past: Critical engagements. Management \& Organizational History, 7(3), 193-202. doi: 10.1177/1744935912444358.

Yaneva, A. (2012). Mapping controversies in architecture. Manchester, UK: Ashgate Publishing Company.

\section{CONTRIBUIÇÕES DOS AUTORES}

Os autores declaram que participaram de todas as etapas de desenvolvimento do manuscrito. A partir da conceituação e abordagem teórico-metodológica, realizou-se a revisão teórica (levantamento bibliográfico), bem como, por fim, redação e revisão final do artigo. 